\title{
Control DC link of single-phase dynamic voltage restorer
}

\author{
Toumi Toufik ${ }^{1}$, Allali Ahmed², Abdelkhalek Othmane ${ }^{3}$, Soumeur Mohammed Amine ${ }^{4}$, \\ Nasri Abdelfatah ${ }^{5}$ \\ 1,3,4,5Faculty of Technology, University of Tahri Mohammed Bechar, Smart Grids \& Renewable Energies Laboratory, \\ Algeria \\ ${ }^{2}$ Faculty of Electrical Engineering, University of Sciences and Technology of Oran, LDDEE, Sustainable Development \\ of Electrical Energy, Algeria
}

\begin{abstract}
Article Info
Article history:

Received Apr 14, 2020

Revised May 23, 2020

Accepted Jul 28, 2020

\section{Keywords:}

Boost converter

Control DC link

Dynamic voltage restorer

PI controller

Voltage sag

Voltage swell

ABSTRACT

This paper is aimed to illustrate and expose the performance of single-phase voltage dynamic voltage restorer (DVR) control connected to the electrical distribution grid. This performance is easily expressed by compensating for the sags and the swells voltages, and regulating the voltage across the load by injecting a voltage component in series with the source voltage increased or decreased with respect to the source voltage the load-side waveforms are purely sinusoidal. The integration of serial and chopper converters makes the DVR capable of bidirectional power flow. The key to this topology is its ability to compensate for sagging and swelling of the voltage in the long run. The modeling of the DVR and the design of its controller is included in this document. Effectiveness of control systems and start-up sequence of DVR operation is verified by detailed simulation studies. The control method used in this work is based on the use of a booster chopper and two cascade loops to generate the PWM command to control the chopper. The effectiveness of the suggested method is confirmed by the MATLAB/SIMULINK ${ }^{\circledR}$ simulation results and some prototype experiments. These results show the capacity of the proposed DC link control.
\end{abstract}

This is an open access article under the CC BY-SA license.

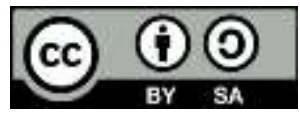

\section{Corresponding Author:}

Toumi Toufik,

Department of Electrical of Engineering,

Tahri Mohammed Bechar University,

BP 417 Route de Kenadsa, 08000 Bechar, Alegria.

Email: toufiktoumi@yahoo.fr

\section{INTRODUCTION}

Industries have achieved a remarkable rate of growth in recent years with sophisticated and advanced computers and equipment. A very good product quality, downsizing and financial gain from this modern industrialization method have opened the door to market for sensitive equipment and control systems, automated manufacturing units and computerized process controls. The significant benefit of the revenues collected has provided these popular systems in the industrial field, whatever their initial cost. Most processes involving this equipment are disrupted by voltage quality issues. The dynamic voltage regulator (DVR) has become in recent years famous as a successful solution for the protection of sensitive loads with voltage sag and swells by injecting the series voltage and the synchronism with the mains supply voltage. The DVR is connected in series with the line via an injection transformer. When a short-circuit fault occurs at load, the voltage on the distribution bus decreases. This causes a dip in the voltage supplied to the sensitive load. To restore the voltage across the load, the DVR is used $[1,2]$. 
The active power provided by the DVR depends on the angle between the charging current Iload and the injected voltage Vinj. In this method, these two vectors are preserved in quadrature, thus ensuring a zero active power injection by the DVR. only the reactive power must be supplied/absorbed by the DVR. So, the energy storage device in the DVR is eliminated, thus limiting the cost. However, the cavity compensation capability is decreased in the case of unit power factor loads. The following equation defines the amplitude of the maximum sag of the voltage that this technique can compensate for:

$$
\Delta V \operatorname{sag} \leq \operatorname{Vl}(1-\cos \beta)
$$

where $V_{L}$ is the rated load voltage and $\cos \beta$ power factor. It is fair that for loads with a weak power factor, it is easier to compensate for the dip of the voltage without real power injection [3-5].

The phase advance method for optimizing the active injection power uses only the phase angle of the charging voltage as a control parameter. However, when the voltage drops considerably, the phase advance method has limits to optimize the active power injected. By using not only the phase angle but also the amplitude of the charging voltage in the voltage tolerance range in order to optimize the active injection power of the DVR. This method has the merit of optimizing the active power injected compared to the conventional method, especially during a deep subsidence [6]. Recently, a method termed single-phase SRFT (Single phase SRF d-q theory) which generates a reference for sthe injected voltage has been proposed and applied to the design of the DVR controller. This controller uses a moving average filter to extract the fundamental component of the positive sequence of the distorted supply voltage and proves very effective in mitigating the voltage sag in distorted supply voltage [7]. In [8-10], the authors presented the design and control of single-phase DVR. With the proposed combination of series and shunt converters, the DVR can provide bidirectional flow of energy. DVRs based on H-bridge converters connected in back-to back configuration with a common dc-link capacitor are commonly used to compensate the load voltage against sag and swell.

In this article, a new and simple DVR-based bridge topology is presented. The proposed DVR scheme can address energy quality issues and the high utilization rate of the DVR, including dynamic voltage compensation in real time. In fact, in normal operating mode, the proposed topology is equivalent to the traditional DVR. In the event of a failure, the DVR is able to immediately limit the current rate of increase. This document is organized as follows. Diagram of the DC link DVR control is proposed in section 2. Section 3 explains the system specification, the mathematical expressions required and control strategy. In section 4, includes a detailed discussion of the results of the simulation during the development of the control DC link of single-phase DVR topology and the conclusions of this work in section 5 conclude this document.

\section{DESIGN OF DVR}

\subsection{Operation of single-phase DVR}

The proposed DVR consists of AC-DC boost and serial converters connected via a common DC capacitor, as shown in Figure 1. The serial converter allows to inject the voltage in series with the mains voltage. The injection of tension is accompanied by an injection transformer. During the voltage drop, a boost converter is used to control the DC link voltage and functions as a booster chopper. The serial converter exerts an action as an inverter and generate a constant alternating output voltage. The supplied voltage is in phase with the mains voltage. During the low voltage, the active power required by the DVR is operated from the source and the energy flow from the shunt converter to the serial converter. Similarly, during voltage swell, the converter-series converter sends energy to the shunt converter. During voltage sag and swell, both converters provide switching frequency voltages with the fundamental component. To filter the switching signals, filters are used at output of series converter.

\subsection{Phase-locked loop}

The phase locked loop (PLL) explained in [9-12] is used to determine a phase angle and the frequency of the grid voltage. These parameters are essential to ensure the performance of systems connected to the network according to predefined standards under abnormal conditions such as voltage sag, voltage swells, notches, phase jumps, harmonics, etc. The principle of PLL is based on generating an orthogonal voltage system. It is a non-linear circuit whose input signal is synchronized with its frequency and phase output signal.

\subsection{Control scheme}

The controllers for the boost and serial converters are illustrated in Figure 2. A cascaded control scheme based on a voltage and current controller is used in the parallel converter. In the serial converters a simple control method is proposed and its efficiency at frequent instances is evaluated by simulation. Voltage distortion and voltage dip as well as over-current are simulated and compensated by an active filter in series with a simple control method. In addition, a single-phase locked loop is used to extract the attitude data. The phase 
locked loop of this document is a good choice for such structures and the handling method is simple and exceptionally robust. In the case of a boost converter, the reference voltage of the intermediate circuit is compared with the actual voltage in order to generate an error. The controller PI processes this error to generate a reference current amplitude multiplied by a sinusoidal signal to generate a reference AC signal [13-16]. The sinusoidal signal is of the same phase and frequency as that of the network voltage and is generated by the PLL. An internal current controller is used to ensure that the alternating current is equal to this reference value.

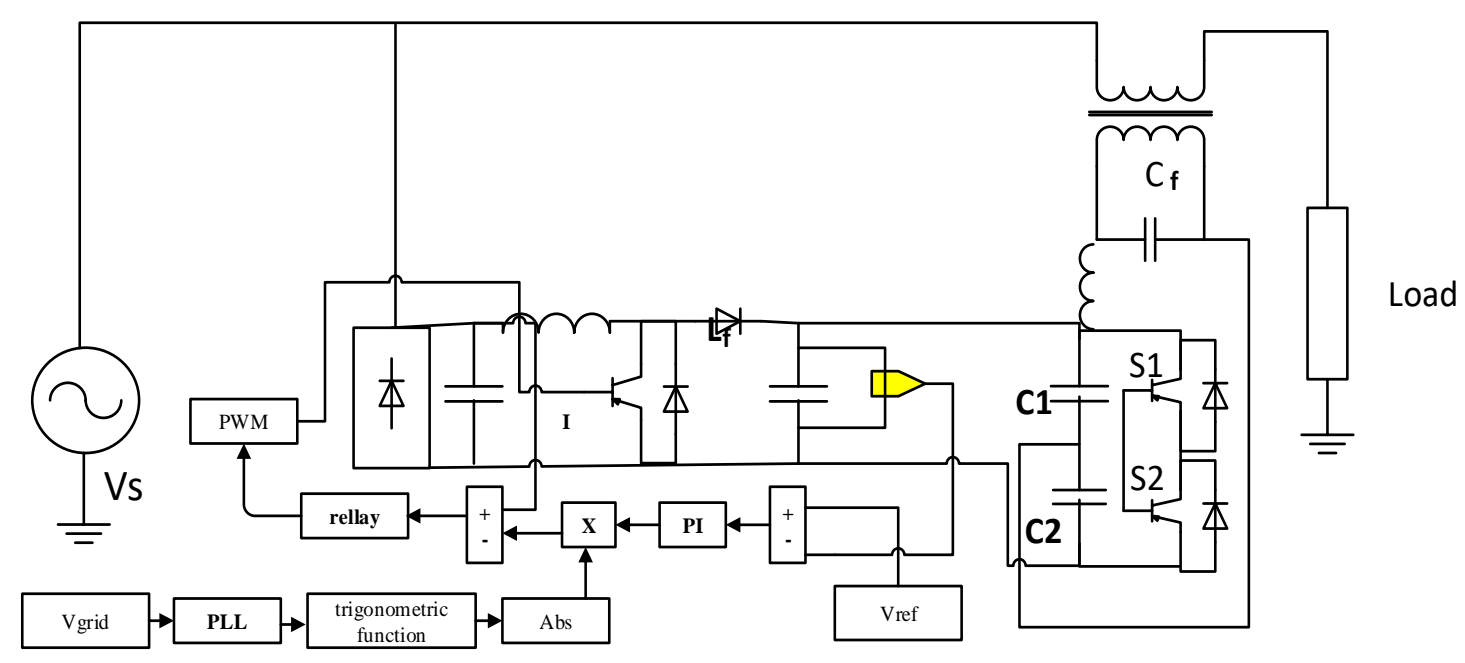

Figure 1. Diagram of the DVR and its control DC link system

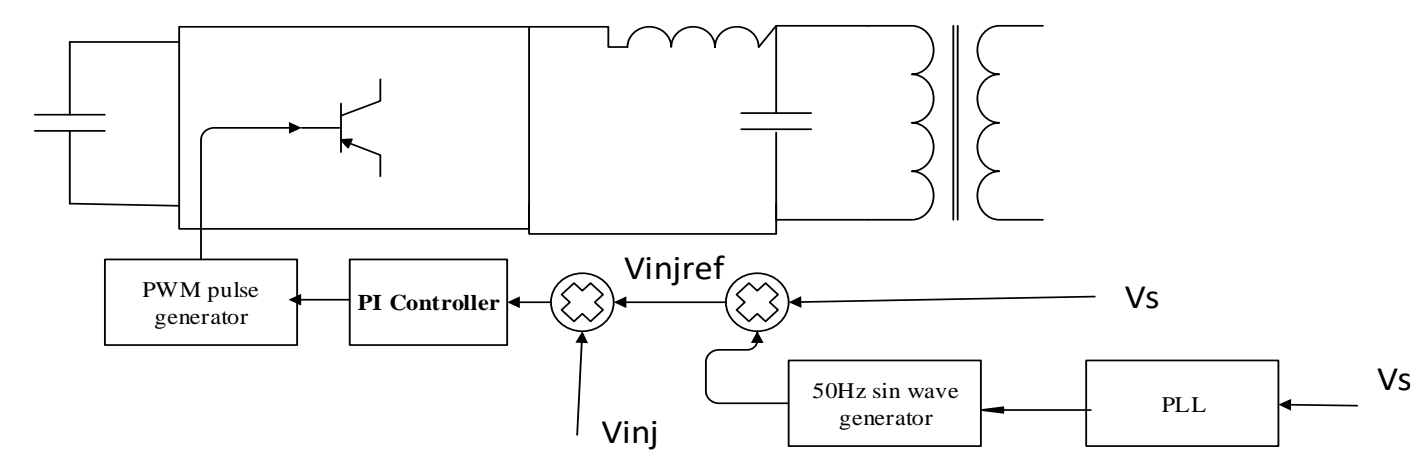

Figure 2. Equivalent circuit of series converter and its block diagram of control scheme

\subsection{Modeling of series and boost converter}

In this section, the mathematical modeling of the series converter is performed. The equivalent circuit of the serial converter is illustrated in Figure 2. Where $\mathrm{V}_{\text {inj }}(t)$ voltage at the charging terminal, the voltage produced by the active filter is injected in series using the device via a transformer. Because in such cases, a high-quality voltage is important, the DC voltage of the active filter is provided by a low power diode rectifier. Figure 2 shows the control approach of the active filter. The reference voltage $V_{\mathrm{s}}(t)-V_{\mathrm{inj}}(\mathrm{t})$ is used by a pulse width modulator to produce it by means of an active filter. The series injected voltage of the DVR can be written as:

$$
\begin{aligned}
& V_{D V R}=V_{L}+Z_{t h} * I_{L}-V_{t h} \\
& I_{L}=\frac{P_{L}+j Q_{L}}{V_{L}}
\end{aligned}
$$

where:

$V_{L}:$ desired load voltage magnitude

$Z_{t h}:$ load impedance

$I_{L}:$ load current

$V_{t h}:$ system voltage during fault condition 
Similarly, the mathematical modeling of the boost converter is performed. The equivalent circuit of the parallel converter is illustrated in Figure 3. It consists of a front-end uncontrolled diode bridge rectifier followed by a standard boost converter [17-20], and it consists of the AC input supply voltage, the input inductance $\mathrm{L}_{\text {in }}$, the capacitor $C$, the supply switch $\mathrm{S}$ (mosfet), the diode D and the output inductance $L_{\text {out }}$. It allows the output voltage to be greater than the input voltage, depending on the ratio D. In the circuit, there is one capacitor storage element.

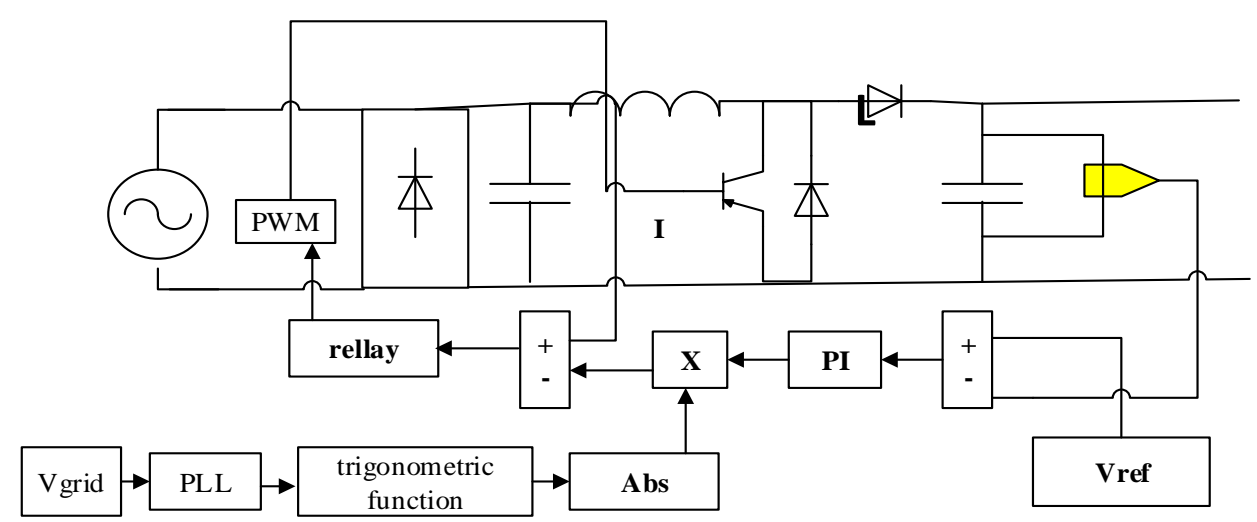

Figure 3. Equivalent circuit of AC-DC boost converter and its control scheme

The boost converter can operate in two modes. The first mode starts when the switch is turned on $\mathrm{t}=0$. The input current increases and crosses the inductor and switches while the second mode starts at $t=t_{O N}$, the input current passes through the inductor, the capacitor, and the diode, the current of the inductor decreases until the next cycle and the energy stored in the inductor flows in the load. In full steady state in time of the voltage of the inductor on the period must be zero, as shown in (3). The values of the different parameters used are presented in Table 1.

$$
V_{\text {in }} * t_{\text {ON }}+\left(V_{\text {in }}-V_{\text {out }}\right) * t_{\text {off }=0}
$$

dividing both sides by $T_{S}$ and rearranging terms we obtain:

$$
\frac{V_{I N}}{V_{O U T}}=\frac{T_{S}}{t_{O F F}}=\frac{1}{1-D}
$$

where:

$V_{\text {in }}$ : input voltage

$V_{\text {out }}$ : average output voltage

$t_{O N}$ : switching on time

$t_{\text {off: }}$ switching off time

$T_{S}$ : switching cycle

D: duty cycle

Table 1. Parameters values of boost converter

\begin{tabular}{cc}
\hline Parameter & Value \\
\hline Input voltage & $7 \mathrm{~V}$ \\
Out voltage & $75 \mathrm{~V}$ \\
Inductance $\mathrm{L}$ & $9.6 \mathrm{e}-04 \mathrm{H}$ \\
Input capacitance $\mathrm{C}_{\text {in }}$ & $0.0041 \mathrm{~F}$ \\
Out capacitance $\mathrm{C}_{\text {out }}$ & $2.3232 \mathrm{e}-05 \mathrm{~F}$ \\
\hline
\end{tabular}

\subsection{Controller PI for series converter}

Figure 4 shows a block diagram of voltage control loop of the series converter [21-22]. The charging voltage is detected and passed through a sequence analyzer. The amplitude of the actual voltage is compared to the reference voltage $\left(V_{r e f}\right)$. If you measure the reference voltage and rms value of the terminal voltage, 
the end result is the PI controller input, which uses the error signal. While the output is considered the angle that leads to the PWM signal generator. The PWM generator then sends the pulse signals to the voltage source converters $\left(V_{S C}\right)$ of the IGBT gates. The PI controller cannot react to changes in the error signal $(\varepsilon)$, it analyzes the instantaneous value of the error signal without taking into account the rise or fall of the error. Mathematically, this practice is called the derived error signal and is characterized by $\Delta \varepsilon$. [23].

\subsection{Controller design for AC-DC boost converter}

The boost converter maintains the DC voltage of the DC link during the voltage drop and swell compensation. The slam voltage is detected using a voltage sensor. The output of the voltage controller is compared with the inductance current of the shunt converter to generate a reference signal. This reference signal maintains a constant DC link voltage. Figure 5 shows à block diagram of the internal current control loop and the external voltage [24, 25].

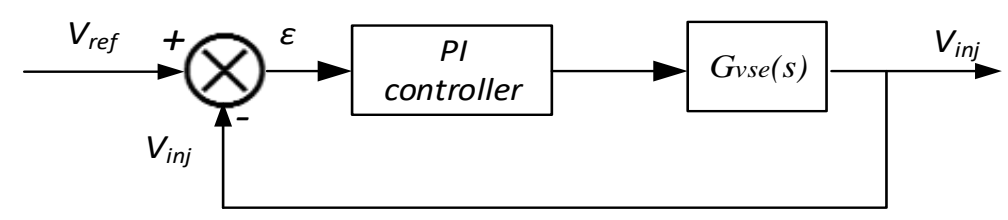

Figure 4. Block diagram of series converter

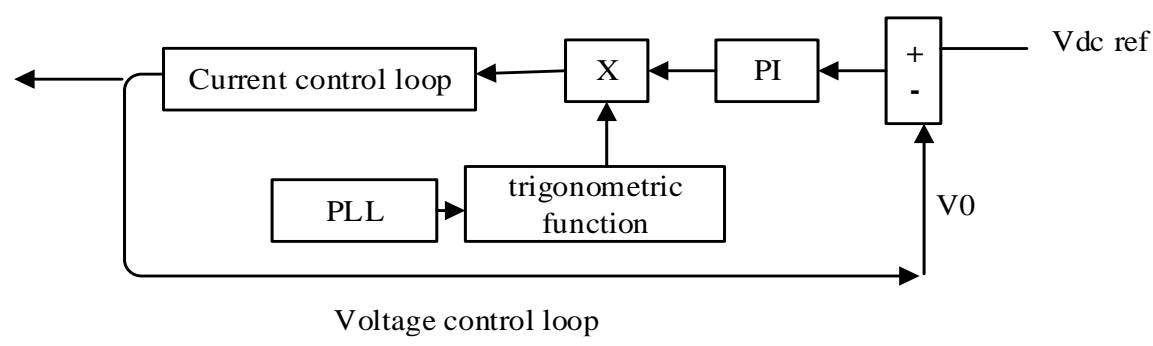

Figure. 5. Block diagram of AC-DC boost converter

\section{DEVELEPEMENT OF CONTROL DC LINK OF DVR}

This DVR is designed to compensate for voltage sag and swell in the range of $3.3 \mathrm{~V}$ (rms) to $10 \mathrm{~V}$ (rms) and maintain the load voltage at $7 \mathrm{~V}$. The DVR is designed for a charge of $50 \mathrm{ohm}$. The nominal power of the injection transformer depends on the voltage to be injected and the load current flowing through the secondary of the injection transformer. The current through the secondary of the injection transformer is the same as that of the load, because they are connected in series. The specifications of the DVR are shown in Table 1. The proposed controller for DVR has been depicted in Figure. 1. To implement the control strategy discussed in the previous sections, a detailed simulation study of the DVR is performed in MATLAB/Simulink. The system and controller parameters are shown in Tables 2 and 3, respectively. The performance of the digital recorder during the conditions of voltage dips and swelling is determined for the linear load.

Tables 2. DVR system parameters in simulation

\begin{tabular}{cc}
\hline Parameter & Value \\
\hline Supply voltage & $7 \mathrm{~V}$ \\
Series transformer & $12 \mathrm{~V} / 230 \mathrm{~V}$ \\
DC link voltage & $75 \mathrm{~V}$ \\
Filter inductance & $24 \mathrm{mH}, 6 \Omega$ \\
Filter capacitance & $1 \mathrm{nF}$ \\
Load resistance & $50 \Omega$ \\
\hline
\end{tabular}

Table 3. Controller parameters in simulation

\begin{tabular}{|c|c|c|c|}
\hline \multirow{2}{*}{ Parameter } & \multicolumn{2}{|c|}{ Voltage loop } & Current loop \\
\hline & $K_{p}$ & $K_{i}$ & $\mathrm{HB}$ \\
\hline AC-DC boost converter & 2 & 30 & 0.001 \\
\hline Series controller & 50 & 20 & \\
\hline
\end{tabular}




\section{RESULTS AND DISCUSSION}

This section presents the results of the simulation and the performance analysis of the DVR. The results of the simulation are presented for a boost converter and series converter. The performance of the DVR during voltage sag and swell conditions is determined for the linear load. Figure 5 shows the performance of the DVR with a resistive load during sags voltage. Up to $0.8 \mathrm{~s}$, the value of the mains voltage is $7 \mathrm{~V}$ (rms value). A swell voltage of the source voltage occurs at $0.4 \mathrm{~s}$. The swell voltage value is 7 $\mathrm{V}$ (rms value) and the duration of the voltage disturbance is 1.2 to $2 \mathrm{~s}$. However, the load voltage remains constant at $7 \mathrm{~V}$ (rms value). During swell, power is transferred from the series converter to boost converter. Similarly, Figure 6 shows the performance of the DVR with network swell voltage for a resistive load.

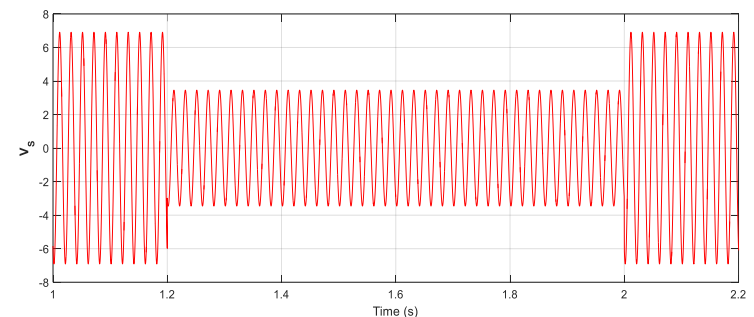

(a)

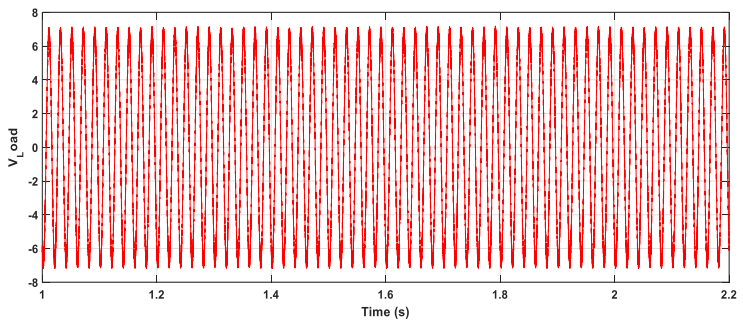

(c)

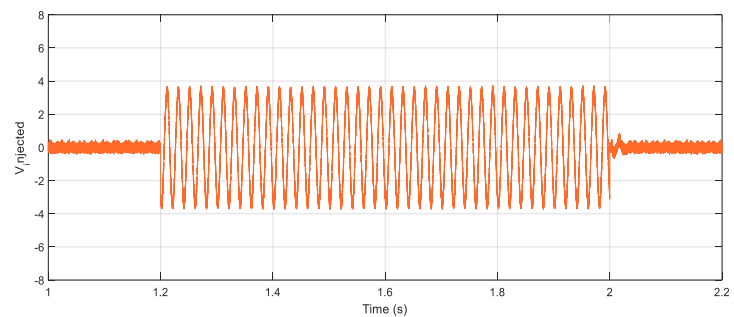

(b)

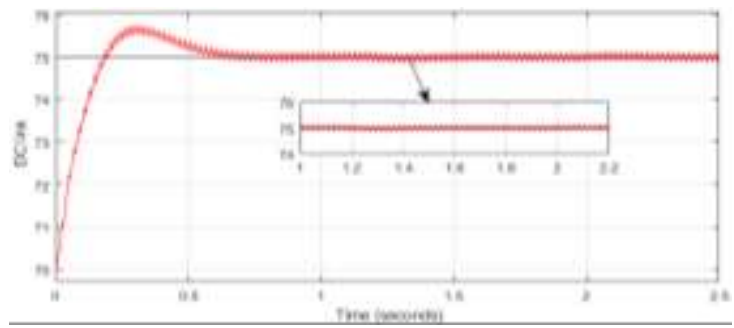

(d)

Figure 5. Single phase voltage sags: (a) Supply voltage, (b) Voltage injected by the DVR, (c) Voltage at load, (d) DC link voltage

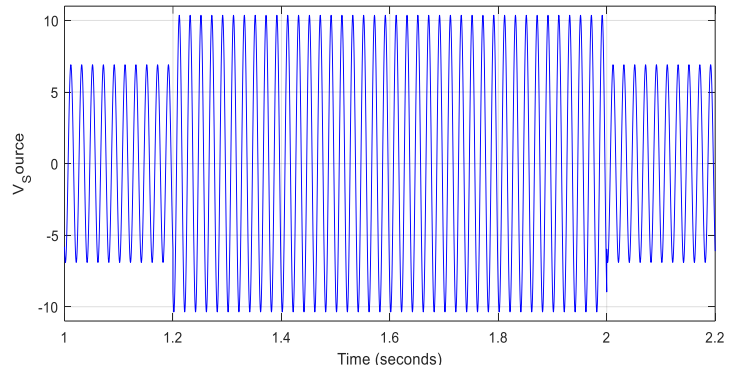

(a)

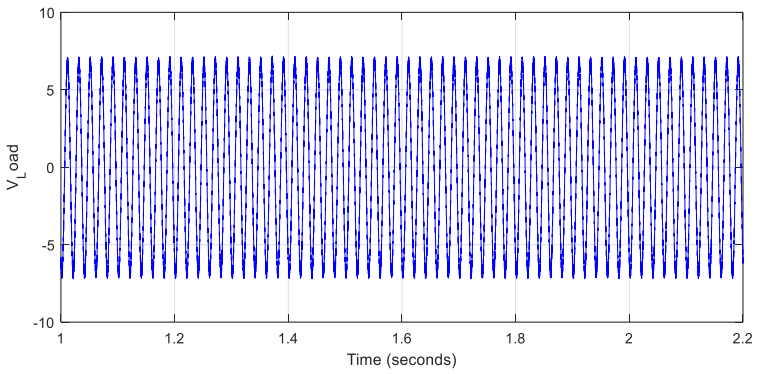

(c)

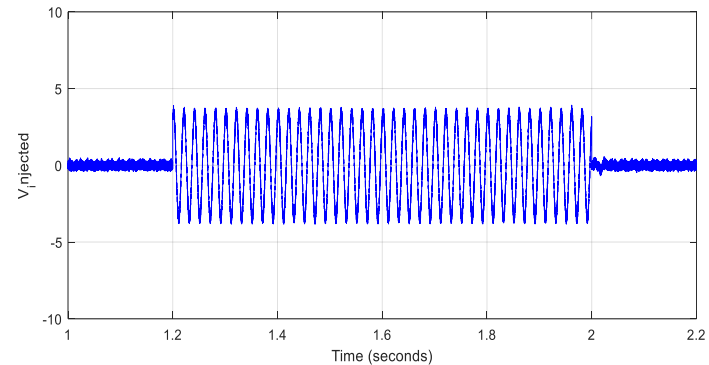

(b)

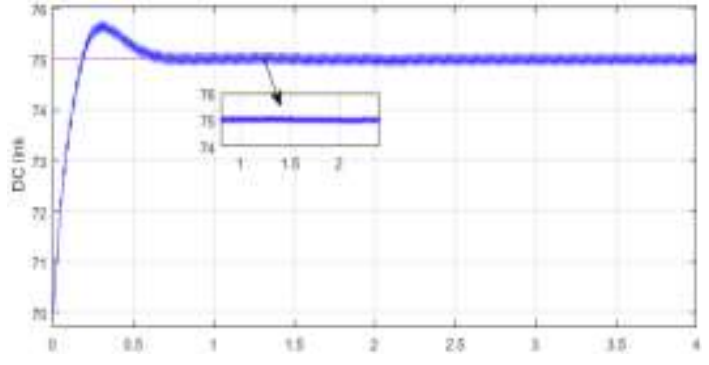

(d)

Figure 6. Single phase voltage swell: (a) Supply voltage, (b) Voltage injected by the DVR, (c) Voltage at load, (d) DC link voltage 
The sag voltage occurs between 1.2 and $2 \mathrm{~s}$. Even during this period, the load voltage is regulated at $7 \mathrm{~V}$ (rms value). During the sag voltage, the actual power goes from the AC-DC boost converter to the serial converter. During transients, the load voltage remains constant, equal to $7 \mathrm{~V}$ (rms value). However, due to load shedding, the DC link voltage increases momentarily. After a duration of $0.8 \mathrm{~ms}$, the DC voltage is restored to its normal value of $75 \mathrm{~V}$. Therefore, it is clear that the AC-AC-AC two-way converter is able to compensate for the sags and swell voltage for linear signals.

\section{CONCLUSION}

Power quality issues, such as troughs and overvoltage, can negatively impact the performance of critical loads. These power quality issues can even cause unwanted deactivation of these loads. To solve these problems, a DVR without energy storage element to compensate for the voltage across the load is designed. Tow converters connected in a back-to-back configuration with a continuous-link current capacitor are used to compensate for the load voltage against sag and swell. the load voltage is compensated by the injection of a series voltage with supply voltage using an injection transformer connected between power supply and load. Converter modeling is discussed and their controllers are designed. The performance of the DVR is tested by detailed simulation studies in MATLAB/SIMULINK. The results of the simulation are shown for the sag and swell with linear load.

\section{ACKNOWLEDGEMENTS}

The authors are thankful to the General Direction of Scientific Research and Technological Development, DGRSDT for providing a research grant.

\section{REFERENCES}

[1] A. Ghosh and G. Ledwich, "Power quality enhancement using custom power devices," London, UK: Kluwer, 2000

[2] K. Perera, D. Salomonsson, A. Atputharajah and S. Alahakoon, "Automated Control Technique for a Single Phase Dynamic Voltage Restorer," 2006 International Conference on Information and Automation, Shandong, pp. 63-68, 2006.

[3] D. M. Vilathgamuwa, A. A. D. R. Perera and S. S. Choi, "Voltage sag compensation with energy optimized dynamic voltage restorer," in IEEE Transactions on Power Delivery, vol. 18, no. 3, pp. 928-936, 2003.

[4] A. D. Falehi and M. Rostami, "Employing of minimum active power injection strategy to compensate voltage sag by DVR," Majlesi J. Elect. Eng., vol. 5, no. 3, pp. 53-61, 2011.

[5] H. K. Al-Hadidi, A. M. Gole and D. A. Jacobson, "Minimum Power Operation of Cascade Inverter-Based Dynamic Voltage Restorer," in IEEE Transactions on Power Delivery, vol. 23, no. 2, pp. 889-898, 2008.

[6] Il-Yop Chung, Dong-Jun Won, Sang-Young Park, Seung-Il Moon and Jong-Keun Park, "The DC link energy control method in dynamic voltage restorer system," International Journal of Electrical Power \& Energy Systems, vol. 25, no. 7, pp. 525-531, 2003.

[7] D. N. Kalote, M. B. Daigavane, S. P. Gawade and P. M. Daigavane, "Analysis, Design and Implementation of Single Phase SRF Controller for Dynamic Voltage Restorer under Distorted Supply," Energy Procedia, vol. 117, pp. 716-723, 2017.

[8] A. Meena, S. Islam, S. Anand, Y. Sonawane and S. Tungare, "Design and control of single-phase dynamic voltage restorer," Sadhana, vol. 42, pp. 1363-1375, 2017.

[9] M. Ciobotaru, R. Teodorescu and F. Blaabjerg, "A new single-phase PLL structure based on second order generalized integrator," 2006 37th IEEE Power Electronics Specialists Conference, Jeju, pp. 1-6, 2006.

[10] X. Cao, W. Chiang, Y. King and Y. Lee, "Electromagnetic Energy Harvesting Circuit With Feedforward and Feedback DC-DC PWM Boost Converter for Vibration Power Generator System," in IEEE Transactions on Power Electronics, vol. 22, no. 2, pp. 679-685, 2007.

[11] M. Vilathgamuwa, A. A. D. Ranjith Perera and S. S. Choi, "Performance improvement of the dynamic voltage restorer with closed-loop load voltage and current-mode control," in IEEE Transactions on Power Electronics, vol. 17, no. 5, pp. 824-834, 2002.

[12] W. Jiang, "Analysis and Design of a Single-Phase PWM Rectifier Based on the Small Signal Model," 2009 International Conference on Information Engineering and Computer Science, Wuhan, pp. 1-4, 2009.

[13] M. H. Bollen, "Understanding power quality problems: voltage sags and interruptions," IEEE press: New York, 2000.

[14] A. Sannino, M. G. Miller and M. H. J. Bollen, "Overview of voltage sag mitigation," 2000 IEEE Power Engineering Society Winter Meeting. Conference Proceedings (Cat. No.00CH37077), Singapore, vol. 4, pp. 2872-2878, 2000.

[15] D. J. Carnovale and T. J. Hronek, "Power quality solutions and energy savings-what is real?," Energy Engineering, vol. 106, no. 3, pp. 26-50, 2009.

[16] N. Athanasiadis, "Power quality solutions for voltage sags using dynamic voltage restorers," Electric Power Components and Systems, vol. 31, no. 2, pp. 159-170, 2003.

[17] J. G. Nielsen, M. Newman, H. Nielsen and F. Blaabjerg, "Control and testing of a dynamic voltage restorer (DVR) at medium voltage level," in IEEE Transactions on Power Electronics, vol. 19, no. 3, pp. 806-813, 2004.

[18] A. Ghosh and G. Ledwich, "Power quality enhancement using custom power devices, " London, UK: Kluwer, 2000. 
[19] K. Perera, D. Salomonsson, A. Atputharajah and S. Alahakoon, "Automated Control Technique for a Single-Phase Dynamic Voltage Restorer," 2006 International Conference on Information and Automation, Shandong, pp. 63-68, 2006.

[20] G. Ramya, V. Ganapathy, P. Suresh, "Power Quality Improvement Using Multi-Level Inverter Based DVR and DSTATCOM Using Neuro-Fuzzy Controller, "International Journal of Power Electronics and Drive Systems (IJPEDS), vol. 8, no. 1, pp. 316-324, March 2017.

[21] Toufik Toumi, Ahmed Allali, Othmane Abdelkhalek, "PV Integrated single-phase dynamic voltage restorer for sag voltage, voltage fluctuations and harmonics compensation, "International Journal of Power Electronics and Drive Systems (IJPEDS), vol. 11, no. 1, pp. 547-554, March 2020.

[22] F. B. Ajaei, S. Afsharnia, A. Kahrobaeian and S. Farhangi, "A Fast and Effective Control Scheme for the Dynamic Voltage Restorer," in IEEE Transactions on Power Delivery, vol. 26, no. 4, pp. 2398-2406, 2011.

[23] P. Thirumoorthi, S. Deepika and N. Yadaiah, "Solar energy based dynamic sag compensator," 2014 International Conference on Green Computing Communication and Electrical Engineering (ICGCCEE), Coimbatore, pp. 1-6, 2014.

[24] M. A. Elgendy, B. Zahawi and D. J. Atkinson, "Assessment of Perturb and Observe MPPT Algorithm Implementation Techniques for PV Pumping Applications," in IEEE Transactions on Sustainable Energy, vol. 3, no. 1, pp. 21-33, 2012.

[25] A. Meftouhi, Othmane Abdelkhalek, Ahmed Allali, A. Benabdelkader, Toufik Toumi, "PV Integrated Series Active Filter for sag voltage and harmonic Compensation," International Journal of Power Electronics and Drive Systems (IJPEDS), vol. 10, no. 3, pp. 1255-1262, September 2019. 